\title{
Coaching Future Entrepreneurs: Features and Success Factors in Vocational Colleges
}

\author{
Zhen Kong ${ }^{1, ~ a}$, Kun Bai ${ }^{2, \text { b, * }}$, Linghan Kong ${ }^{3}$ \\ ${ }^{1}$ Beijing Information Technology College, No. 5, Fangyuanxilu, Chaoyang District, \\ Beijing, China \\ ${ }^{2}$ University of International Relations, No. 12, Poshangcun, Haidian District, \\ Beijing, China \\ ${ }^{3}$ Beijing Bayi School, No. 29, Suzhoujie, Haidian District, Beijing, China \\ ${ }^{a}$ Kongz@bitc.edu.cn, ${ }^{b}$ Baikun@uir.edu.cn \\ *Corresponding author
}

\begin{abstract}
This article is aimed at those Chinese vocational colleges looking for advice, ideas and inspiration for the effective entrepreneurship mentoring. At present, entrepreneurship education in vocational college is relatively lagging behind. Colleges should provide services and security for the students to achieve entrepreneurial success. Entrepreneurial coaching appears to be a sufficiently customized way to help novice owner-managers develop their managerial skills. However, its usefulness remains to be verified. The research is thus to examine the effectiveness of coaching as a support measure for young entrepreneurs and to identify the factors likely to have an impact on the success of coaching initiatives.
\end{abstract}

KEYWORDS: Student; Vocational college; Mentoring; Coaching

\section{Introduction}

Colleges play several roles in their communities and one of their key functions is to support and drive regional, social and community development. To score highly, colleges should be active players, linked to their external environment by having a strong presence in the community. This might include for example, providing mentoring and coaching for future entrepreneurs from inside and outside the institution, participating in regional clusters, supporting local innovation activities, providing opportunities for regional start-ups or established companies and taking an active role in determining the strategic direction of local development. Beijing Information Technology College(BITC) is a vocational school in Beijing (The People's Republic of China. It offers education to 7,000 students and it employs around 800 people. It provides all the education and skills required so that each individual achieves its full potential and will become - and remain - ready for the 
current innovation and entrepreneurship. An important factor for the success of education is the degree of innovation and co-creation. The staff demonstrate an entrepreneurial attitude during and after their work. Also, we see a growing group of students that embraces entrepreneurship. Therefore, entrepreneurship is one of the strategic lines of this college.

\section{Active Coaching}

It has been recognized that learning outcomes can be divided into three general categories: Cognitive, skill-based, and affective learning. Moreover, vocational colleges offer active mentoring-inspired support programs to novice entrepreneurs starting a business. We have coded 100 learning outcomes acquired by novice entrepreneurs through their mentoring relationship. These learning outcomes were analyzed using the three general categories and linked with the mentor's way of promoting learning. Cognitive learning accounts for $62 \%$ of total learning outcomes and affective learning makes up 35\%, which leaves skill-based learning in a marginal position. In addition, methods used by the mentor to ensure mentee learning affect learning content. Mentees were also asked to describe the benefits of their mentoring relationship through discussion groups. From a cognitive learning standpoint, benefits reported by entrepreneurs include an increase in management knowledge and skills, improved vision for their business venture and identifying new opportunities. Benefits resulting from affective learning include a greater sense of self-efficacy, validation of one's entrepreneurial self-image and a lowered sense of solitude, all factors that could ultimately influence entrepreneur resilience. These results reveal the scope and limitations of mentoring as means to support learning. Active mentoring enables students to approach their startup as if learning a musical instrument, applying "the musician mindset" as means to collaboration and creative problem solving. There's more to entrepreneurship than business plans and spreadsheets much like there's more to music than scales and lead sheets. Therefore, students approach entrepreneurship as a creative process, a fundamental human instinct that we all possess and can unlock. Creativity \& Entrepreneurship applies concepts from the creative and musical creation process, such as observing, prototyping, iterating and embracing failure, as a means of guiding somebody through the concept of thinking like a startup. Students will develop the basic mindset, knowledge, and insights required to pursue an entrepreneurial career, whether as the steward of their own career or as the founder of a new business in any field. We have observed that mentoring offers an opportunity for young entrepreneurs to mainly develop cognitive and affective learning. In a context where he may experience some difficulty in obtaining proper training, particularly due to a lack of time and resources, which are often a by-product of starting up a business, this type of support may help him meet some of his needs. Mentoring is particularly helpful in allowing a transfer of knowledge about the business world, and developing a competence set that will be useful to the entrepreneur, within the limits of what the mentor can offer. Moreover, we have observed that some entrepreneurs had developed an improved vision for their business and others had identified new business opportunities to pursue. 


\section{Entrepreneur Scan}

Students have the opportunity to do an entrepreneur scan (intake, scan, discussion of results and interpretation). This scan provides the students knowledge about their entrepreneurial skills and competences as well as stimulating activities. As a follow up, students start a series of coaching sessions with a coach to increase their skills and competences. After these sessions the student can decide to write a bank proof business case under the guidance of his/her coach. We offer the student an online platform to write the case. If students lack the knowledge to write a good business case, they can sign up for various classes. It is crucial for the college to invest in its entrepreneurial activities through a sustainable financial strategy, but it is not good to be over reliant on limited sources of public funding. Colleges are entrepreneurial when they are not afraid to maximize their potential. All staff and students are important internal stakeholders supporting the entrepreneurial agenda. All parts of the college have to work together, creating synergies and linkages across faculties, departments and other structures, breaking down traditional boundaries and silos. To score highly colleges should have mechanisms in place for exploiting internal knowledge and resources through, for example, shared facilities across faculties. For example, BITC offers a program for students to run a student company Students develop their entrepreneurial attitude and skills in a practical way (learning by doing). On campus BITC have various opportunities where they can run their business and sell their products. An expert group supports the different domains in the program responsible for the alignment between the different teaching teams, support for the development of entrepreneurship education, guest lectures and entrepreneurship contests. The college is committed to fostering student entrepreneurship and entrepreneurial thought leadership. Through its unique results-driven approach to entrepreneurship education, the college offers supports programs to nurture student-run businesses and provides a research environment where entrepreneurial thinking flourishes. Entrepreneurship education benefits students to think outside the box and nurtures unconventional talents and skills.

\section{Entrepreneurial Coaching}

Entrepreneurial coaching appears to be a sufficiently customized way to help novice owner-managers develop their managerial skills. However, its usefulness remains to be verified. Given the exploratory nature of the study, a flexible and open approach was chosen in order to explore the concept of coaching in some depth. The strategy retained was the case study method, with inter-site comparisons of six coaching initiatives. The findings suggest that the success of a coaching relationship is explained by a set of factors or "winning conditions", some of which are more important than others. The most crucial one appears to be the entrepreneur's open attitude to change. The Incubator manager also plays a significant information provision role. It is up to him to give the right instructions to the coaches, who usually have no prior experience of coaching. The Incubator's coaching program must also be explained to the entrepreneurs. The concept of coaching does not appear to be a familiar one, and this can cause entrepreneurs to develop unrealistic 
expectations of their coach. This happened in the two sample cases classified as unsuccessful; the entrepreneurs expected and actually wanted the coaches to behave as consultants and solve the problems for them. Another interesting aspect of the support structure is the speed of intervention. The entrepreneurs interviewed for the research said they were used to long delays when dealing with government services. The fact that the coaching initiative was set up within a week of their initial contact with the Incubator suggests a level of efficiency in stark contrast to the heavy bureaucracy associated with the government apparatus. This created a favorable image of the Incubator among an audience that tends to be mistrustful and cynical of government services in general. All the entrepreneurs in our sample said they were generally satisfied with their coaches in this respect. It would thus appear that even when coaches possess all the desired attributes, the relationship can still end in failure, as was the case on two occasions. This suggests that these qualities are necessary for success to be achieved, but not the main reason for it. Being receptive to coaching and especially being open to change seem to be the main conditions for coaching success. Commitment to the relationship also appears to be a major success factor. Short-term goals also enable the parties to measure their progress weekly and make adjustments where necessary. Among the wide range of tools available to entrepreneurs, coaching is increasingly popular as a support structure. Entrepreneurs are therefore exposed to rather standardized forms of knowledge that are unlikely in themselves to enable them to adapt to future changes. Coaching, on the other hand, encourages entrepreneurs to put their own strategic vision into action. The entrepreneur is invited to think differently rather than simply absorb advice on the basis of past cognitive schemes. Entrepreneurial coaching thus has a majestic role in the entrepreneurial process. The teachers' efforts are the vital part of improving the attraction and infectivity of coaching. They play an important role in the process of constructing the school culture to boost innovation. Therefore, we must strengthen and improve the new ways and new methods of mentoring and coaching.

\section{Summary}

Coaching can also help improve various affective learning aspects including self-image, self-efficacy and resilience in the face of difficulties. Mentors, by their approach to the mentoring relationship, can contribute to the development of certain types of learning. Where discussions, explanations, questioning, and working together are especially useful to the development of cognitive learning, encouragement and modeling foster the development of affective learning. Mentors should therefore be sensitized as to the specifics of their role and adapt their approach according to the needs expressed by the novice entrepreneur in order to facilitate desired learning outcomes. This research has provided key success factors for entrepreneurial coaching. It would also be appropriate to look in more depth at the role of the third person overseeing the coaching relationship, who is in an ideal position to influence the relationship and improve its chances of success. This learning can help correct a number of problems and difficulties experienced by novice entrepreneurs. Mentoring therefore constitutes an adaptable and versatile 
form of support that can be of tremendous benefit to future entrepreneurs. By the same token, mentor roles, mentoring frequency and duration, as well as the psychological characteristics of the participants are all likely to influence coaching. Better knowledge of these aspects would help explain the ways in which they develop, and contribute to the improvement of coaching as well as formal entrepreneur coaching programs. Further insight into these issues would allow for a better understanding of the role coaching plays in the life of a novice entrepreneur.

\section{Acknowledgements}

This research was financially supported by Beijing Information Technology College Research Subject.

\section{References}

[1] Josée Audet, Coaching the entrepreneur: features and success factors[J].Journal of Small Business and Enterprise Development,2012-03-31.

[2] Etienne St-Jean, The role of mentoring in the learning development of the novice entrepreneur[J]. International Entrepreneurship and Management Journal, 2012-01-31.

[3] Williams, G., and I. Kitaev, Overview of national policy contexts for entrepreneurialism in higher education institutions[J].Higher Education Management and Policy, 2005 (3): 125.

[4] Thorp, H. and Goldstein, B, Engines of Innovation: The Entrepreneurial University in the Twenty-First century[M].Chapel Hill, University of North Carolina Press, 2010. 